\title{
NOTA SOBRE A DISTRIBUIÇÃO GEOGRÁFICA DE PELTOPHORUM DUBIUM (SPRENG.) TAUB. NO RIO GRANDE DO SUL ${ }^{1}$
}

\author{
JOSÉ NEWTON CARDOSO MARCHIORI² FABIANO DA SILVA ALVES ${ }^{3}$
}

\section{RESUMO}

É analisada a distribuição geográfica da canafístula (Peltophorum dubium (Spreng.) Taub.) no estado do Rio Grande do Sul. A espécie, uma das mais representativas da Floresta Estacional do Alto Uruguai, acompanha a mata ciliar do grande rio até o município de Barra do Quaraí, alcançando o departamento uruguaio de Artigas e o nordeste da província argentina de Entre Rios.

Palavras-chave: Caesalpiniaceae, Caesalpinioideae, Fabaceae, Leguminosae, Peltophorum dubium, Flora do Rio Grande do Sul.

\section{ABSTRACT}

[The geographic distribution of Peltophorum dubium (Spreng.) Taub. in Rio Grande do Sul state, Brazil].

The geographic distribution of Peltophorum dubium (Spreng.) Taub. (Fabaceae) in Rio Grande do Sul state (Brazil) is presently discussed. One of the most representative trees in Upper Uruguay Seasonal Forest, the species also grows along Uruguay river bordering forest up to the municipality of Barra do Quaraí, reaching the uruguayan department of Artigas and the northeast of Entre Rios province, in Argentina.

Key words: Caesalpiniaceae, Caesalpinioideae, Fabaceae, Leguminosae, Peltophorum dubium, Flora of Rio Grande do Sul.

\section{INTRODUÇÃO}

Árvore ornamental e de madeira valiosa, a canafístula (Peltophorum dubium (Spreng.) Taub.) é uma das espécies mais conspícuas na Floresta Latifoliada do Alto Uruguai, tanto pelo grande porte de seus indivíduos, que integram o dossel, como pela vistosa florada estival.

Motivo de informações desencontradas na literatura sul-rio-grandense, o presente trabalho tem o objetivo de analisar a distribuição geográfica desta importante essência florestal e madeireira no Rio Grande do Sul, à luz de observações pessoais e de referências bibliográficas, com o singelo objetivo de contribuir ao esclarecimento do tema.

1 Recebido em 10-8-2011 e aceito para publicação em 28-9-2011.

2 Engenheiro Florestal, Dr. Professor Titular do Departamento de Ciências Florestais, Universidade Federal de Santa Maria. Bolsista de Produtividade em Pesquisa (CNPQ - Brasil).

Biólogo, MSc. Professor da Universidade da Região da Campanha (URCAMP - Alegrete). Doutorando do Programa de Pós-Graduação em Engenharia Florestal, UFSM.

\section{REVISÃO DE LITERATURA}

Com base em farta documentação bibliográfica, Carvalho (2003) indica que a canafístula (Peltophorum dubium (Spreng.) Taub.) apresenta ampla distribuição natural no Brasil, ocorrendo desde o estado da Paraíba $\left(7^{\circ} \mathrm{S}\right)$ até a latitude de $29^{\circ} \mathrm{S}$, no Rio Grande do Sul, atingindo seu limite austral em Artigas (30 $\left.25^{\prime} \mathrm{S}\right)$, no Uruguai ${ }^{4}$. De acordo com Siminski et al. (2011), a espécie cresce em altitudes que variam de 30 m sobre o nível do mar (Rio de Janeiro) até 1300 m (Minas Gerais), sendo frequiente nas florestas estacionais Semidecidual e Decidual, bem como no Cerradão e em encraves da região Nordeste e Pantanal.

A partir de coletas realizadas na "Floresta Pluvial do Rio Uruguai", no noroeste do Rio Grande do Sul, Rambo (1966) informou que a espécie se estende até a República do Uruguai ${ }^{5}$.

De acordo com Reitz et al. (1983), a canafístula é espécie restrita à "Floresta Latifo-

4 CARVALHO, P.E.R. Espécies arbóreas brasileiras. Brasília: Embrapa Informação Tecnológica, 2003. v. 1. p. 284.

"Rain forest belt in the bend of the Upper Uruguay River 


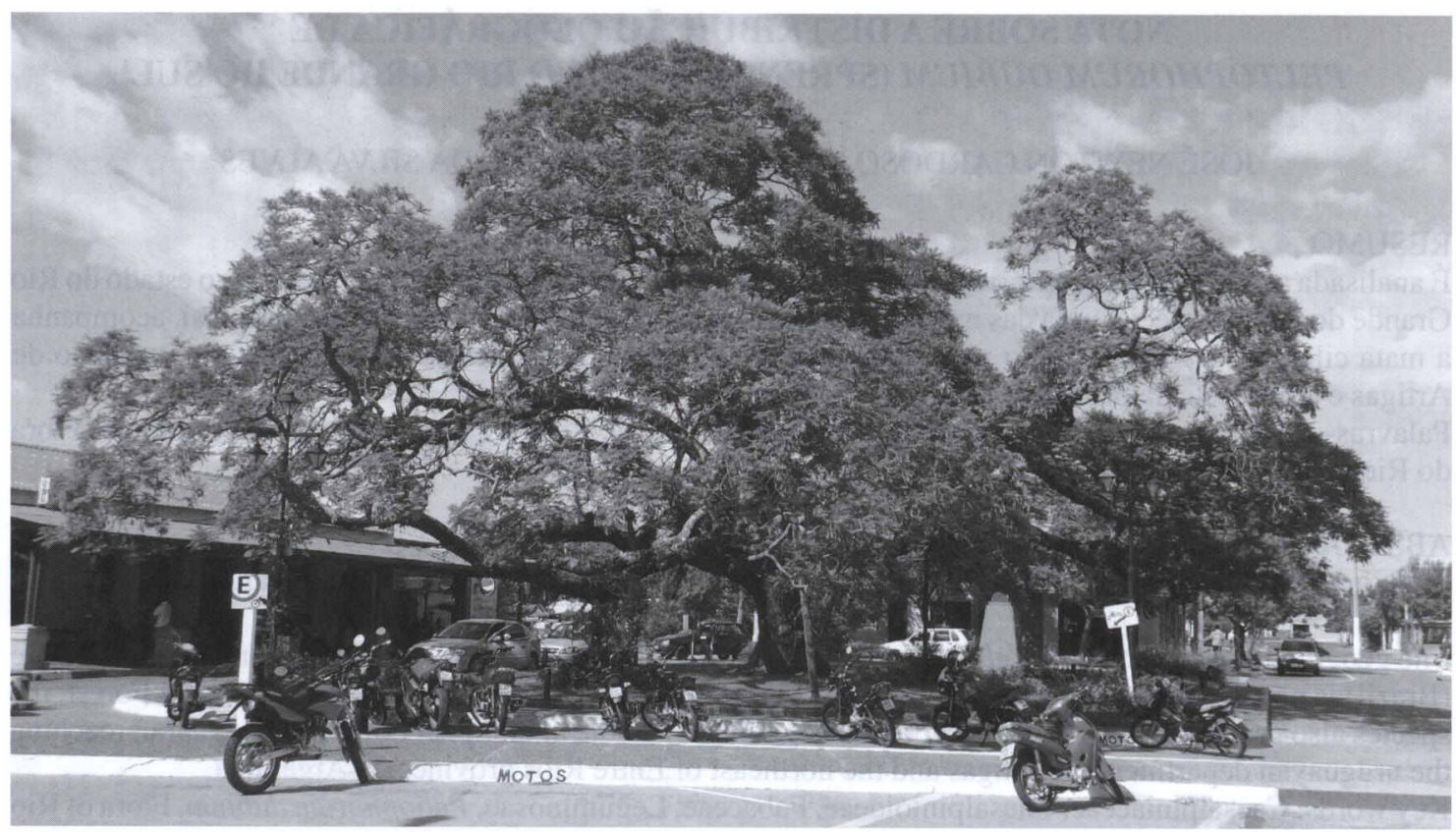

FIGURA 1 - Canafístula de grande porte, frente ao Terminal de Artigas, Uruguai (antiga estação ferroviária da cidade). O texto afixado em placa ao pé da árvore ressalta a importância histórica do indivíduo, por sua vinculação ao prócer uruguaio (Retoño directo del que brindara protección al Prócer en sus años de exilio).

liada do Alto Uruguai”, ocorrendo desde Marcelino Ramos, Nonoai, Palmeira, Tenente Portela, Santa Rosa e Santo Ângelo, até São Borja $^{6}$, município referido como "limite austral da espécie no Brasil". Embora "não muito freqüente" no Estado, os autores referem-se à árvore como uma das mais características na tipologia florestal em que se encontra, devido a seu grande porte e vistosas inflorescências terminais ${ }^{7}$. De maior interesse, no presente caso, é a indicação da ocorrência pretérita de "algumas gigantescas canafístulas" no município de

down to the Republic of Uruguay" (RAMBO, B. Leguminosae riograndenses. Pesquisas, Botânica, São Leopoldo, n. 23, p. 65, 1966).

6 No mapa de distribuição geográfica apresentado pelos autores (Reitz et al, 1983. Op. cit., p. 198), o município de São Borja é o único assinalado, ao sul da Região Fitogeográfica do Alto Uruguai. Resta acrescentar que os referidos autores incluíram os municípios de São Nicolau, São Borja e Itaqui na região fitogeográfica da "Bacia do Rio Ibicuî".

REITZ, R.; KLEIN, R.M.; REIS, A. Projeto Madeira do Rio Grande do Sul. Sellowia, Itajaí, n. 34-35, 1983, p. 197.
Rolante, na bacia do Rio dos Sinos; a este respeito, Reitz et al. (1983) informam que não encontraram a espécie na Bacia do Rio Jacuí, apesar das "meticulosas e atentas observações" realizadas no ano de $1981 .^{8}$

Na área do "Parque Estadual do Espinilho", município de Barra do Quaraí, Galvani (2003) assinalou a presença da canafístula "junto às margens do rio Uruguai", ressaltando ser esta a primeira citação da espécie "na fronteira oeste do Rio Grande do Sul"9.

Em contraponto a registros anteriores, Sobral et al. (2006) afirmam que no Rio Grande do Sul a espécie se encontra apenas na Floresta do Alto Uruguai $^{10}$.

8 REITZ et al., 1983. op. cit,, p. 198.

9 GALVANI, F.R. Vegetação e Aspectos ecológicos do Parque Estadual do Espinilho, Barra do Quaraí, RS. Porto Alegre: Universidade Federal do Rio Grande do Sul, 2003. Tese de Doutorado (Programa de Pós-Graduação em Botânica). f. 67.

${ }^{10}$ SOBRAL, M.; JARENKOW, J.A.; BRACK, P., IRGANG, B., LAROCCA, J.; RODRIGUES, R.S. Flora arbórea e arborescente do Rio Grande do Sul, Bra- 


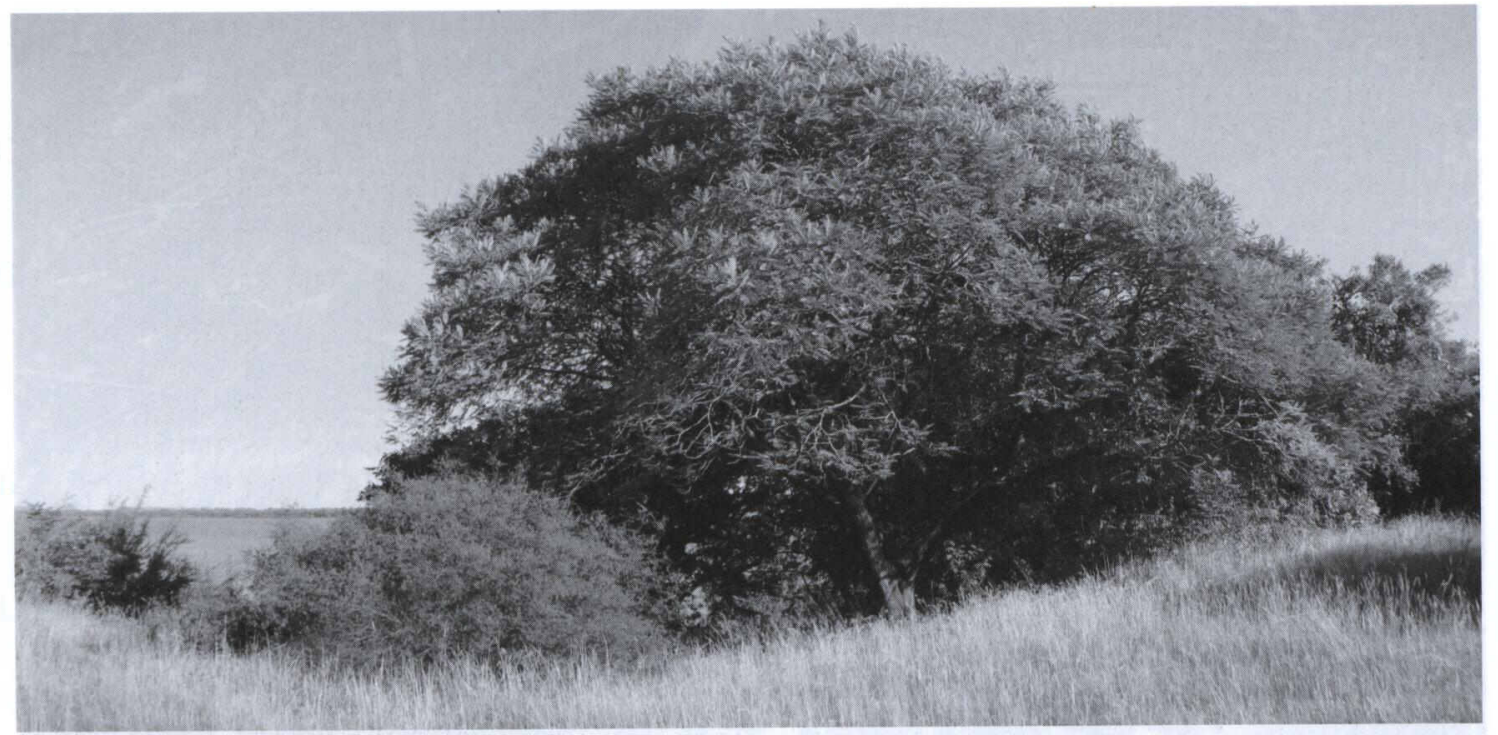

FIGURA 2 - Canafístula de grande porte na mata ciliar do rio Uruguai, em Barra do Quaraí, próximo ao monumento que assinala a fronteira do Brasil com o Uruguai e a Argentina.

Para a República Oriental do Uruguai, o registro pioneiro se deve a Lombardo (1943), que assinalou a ocorrência natural de Pelthophorum dubium tanto na costa como em ilhas do rio Uruguai, no departamento de Artigas ${ }^{11}$. O autor comenta que a espécie, até então considerada exótica, é conhecida localmente pelos nomes populares de ibirapitá e árbol de Artigas, o último dos quais devido a sua estreita vinculação com Dom José Gervasio Artigas, herói uruguaio que viveu exilado seus últimos anos de vida no Paraguai $^{12}$. Acerca do tema, Izaguirre \& Beyhaut (2003) acrescentam ser comum o cultivo de indivíduos da espécie em escolas e comisarías rurais do país, como homenagem a Artigas (Figura 1). Brussa \& Grela (2007), por sua vez, referem a ocorrência natural de Pelto-

sil, São Carlos: RiMa : Novo Ambiente, 2006. p. 112.

${ }^{11}$ LOMBARDO, A. Noticia de la vegetación de la costa oriental del Río Uruguay en los departamentos de Paysandu, Salto y Artigas. Comunicaciones Botánicas del Museo de Historia Natural de Montevideo, n. 4, p. 4, 1943.

12 Diz-se que Artigas costumava matear à sombra de uma frondosa canafístula existente no pátio de sua casa, nos arredores de Assunção, local atualmente incorporado ao Jardim Botânico da cidade. phorum dubium em bosques ribeirinhos do rio Uruguai, no departamento de Artigas.

Para a Argentina, Burkart (1987) informa que a espécie vegeta em ilhas e partes altas da margem do rio Uruguai, no nordeste da província de Entre Ríos (Concórdia, Federación) ${ }^{13}$.

\section{DISTRIBUIÇÃO NO RIO GRANDE DO SUL}

Árvore típica da Floresta Estacional do Alto Uruguai, a canafístula também participa, no Rio Grande do Sul, da composição da mata ciliar adjacente ao grande rio, alcançando o sul do departamento uruguaio de Artigas e o nordeste da província argentina de Entre Rios, onde se encontra o limite austral de distribuição da espécie.

Na mata ciliar, a canafístula habita as partes média e alta dos barrancos, como bem salientado por Burkart (1987), locais somente alcançados pelas grandes enchentes, crescendo juntamente com o ingazeiro (Inga vera Willd.), o pessegueiro-do-mato (Eugenia myrcianthes

\footnotetext{
${ }^{13}$ BURKART, A. Leguminosae (= Fabaceae), Leguminosas. In: BURKART, A.; BURKART, N.S.T. de; BACIGALUPO, N.M. Flora Ilustrada de Entre Ríos (Argentina). Buenos Aires: INTA, 1987. p. 530.
} 


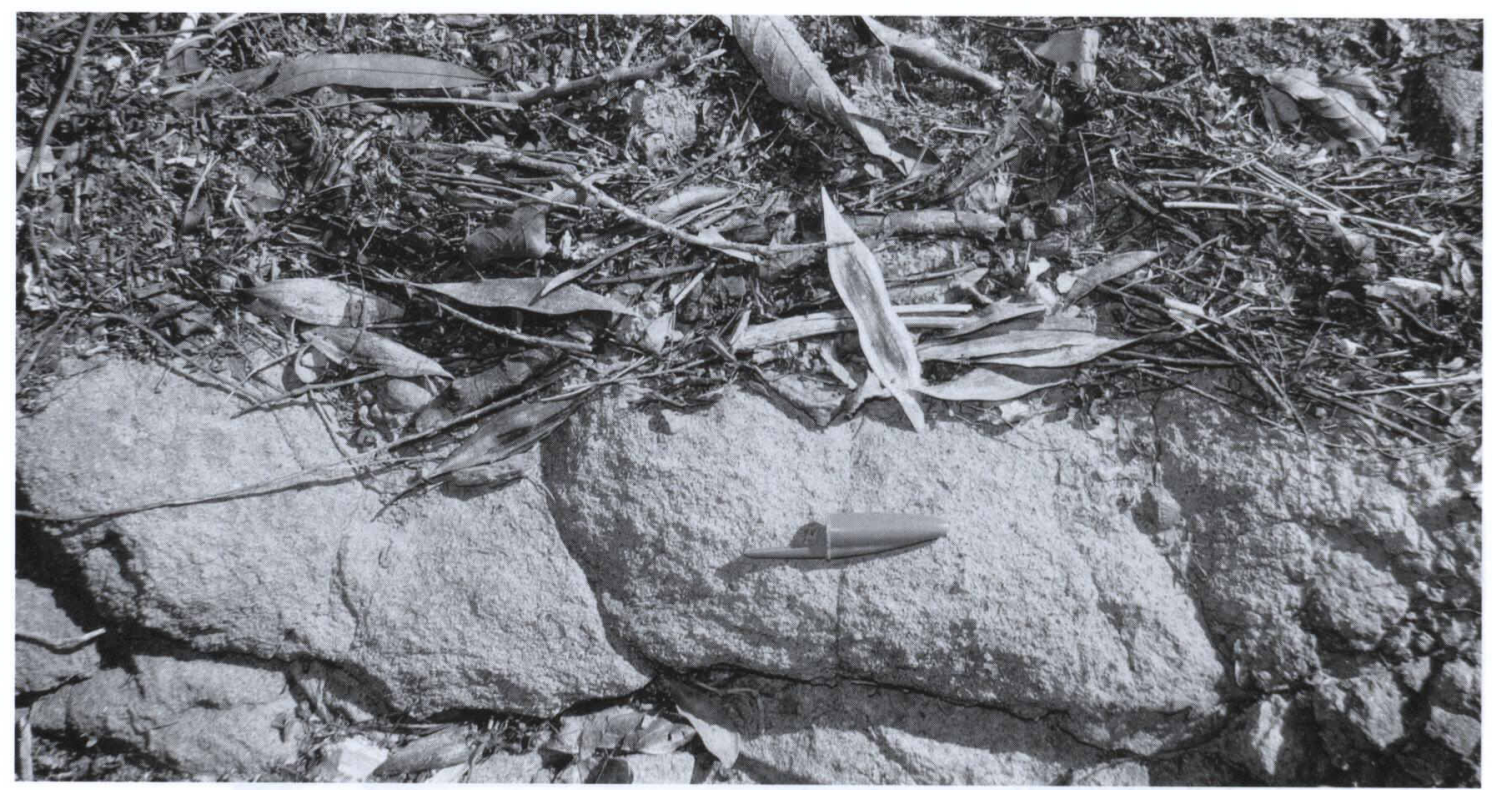

FIGURA 3 - Frutos de Peltophorum dubium junto a detritos deixados na barranca do rio Quaraí, por ocasião de uma enchente (município de Barra do Quaraí).

Nied. $)^{14}$, o açoita-cavalo (Luehea divaricata Mart.), o ipê-roxo (Handroanthus heptaphyllus (Vell.) J. Mattos), o angico (Parapiptadenia rigida (Benth.) Brenan) e a guajuvira (Cordia americana), entre outras espécies arbóreas de porte médio a grande.

A canafístula é ornamento conspícuo na mata ciliar do rio Uruguai (Figura 2), sobretudo de dezembro a abril, quando o amarelo de sua abundante floração contrasta com o verde das outras árvores do dossel. Nas regiões fisiográficas das Missões e Campanha, a espécie não se encontra senão no trecho final dos afluentes do rio Uruguai, casos do Ibicuí e Quaraí, fato sugestivo de eficiente dispersão hidrocórica, apesar dos frutos alados, próprios da espécie, serem tradicionalmente associados à anemocoria ${ }^{15}$. Cumpre salientar que os legumes samaróides persistem nos ramos após a queda completa das folhas no outono, de modo que, dispersos inicial-

${ }^{14}$ Por vezes, esta espécie consta, na literatura, como Hexachlamys edulis (O. Berg) Kausel \& D. Legrand, binômio atualmente reduzido à sinonímia.

${ }^{15}$ De acordo com Carvalho (2003), a canafístula é autocórica, principalmente barocórica (por gravidade) e anemocórica (Op. cit., p. 284). mente pelo vento, eles acabam por ser transportados pelas águas, rio abaixo. Vale notar que esta dispersão, verificada em meados do inverno e início da primavera (de junho a outubro), coincide com período de freqüentes cheias do rio. De longa vitalidade, as sementes são comumente encontradas nos barrancos, junto a detritos deixados pelas águas (Figura 3).

Do acima exposto, conclui-se que a canafístula, no Rio Grande do Sul, tem distribuição restrita à Floresta Estacional do Alto Uruguai e à mata ciliar deste rio até o extremo sudoeste do Estado, no município de Barra do Quaraí. Indivíduos jovens e de grandes dimensões são facilmente reconhecidos na estrutura da mata ciliar, mesmo em trechos próximos às pontes internacionais que ligam São Borja e Uruguaiana à Argentina.

\section{REFERÊNCIAS BIBLIOGRÁFICAS}

BRUSSA SANTANDER, C.A.; GRELA GONZÁLEZ, I.A. Flora arbórea del Uruguay. Con énfasis en las especies de Rivera y Tacuarembó. Montevideo: Cofusa, 2007. 542 p.

BURKART, A. Leguminosae (= Fabaceae), Leguminosas. In: BURKART, A.; BURKART, 
N.S.T.; BACIGALUPO, N.M. Flora Ilustrada de Entre Ríos (Argentina). Buenos Aires: INTA, 1987. v. 6. 763 p.

CARVALHO, P.E.R. Espécies florestais brasileiras. Brasília: Embrapa Informação Tecnológica, 2003. v. 1. 1039 p.

GALVANI, F.R. Vegetação e aspectos ecológicos do Parque Estadual do Espinilho, Barra do Quaraí, RS. 132 f. Porto Alegre: Universidade Federal do Rio Grande do Sul, 2003. Tese de Doutorado (Programa de Pós-Graduação em Botânica).

IZAGUIRRE, P.; BEYHAUT, R. Las Leguminosas en Uruguay y regiones vecinas. Montevideo: Editorial Hemisferio Sur, 2003. 301 p.

LOMBARDO, A. Noticia de la vegetación de la costa oriental del Río Uruguay en los departamentos de Paysandu, Salto y Artigas. Comunicaciones Botánicas del Museo de Historia Natural de
Montevideo, n. 4, p. 1-9, 1943.

RAMBO, B. Leguminosae riograndenses. Pesquisas, Botânica, São Leopoldo, n. 23, p. 1-50, 1966.

REITZ, R.; KLEIN, R.M., REIS, A. Projeto Madeira do Rio Grande do Sul. Sellowia, Itajaí, n. 3435, p. 1-525, 1983.

SIMINSKI, A.; SCHUCH, C.; FANTINI, A.C.; CANCI, I.J. Peltophorum dubium, Canafístula. In: CORADIN, L.; SIMINSKI, A.; REIS, A. (Ed). Espécies nativas da flora brasileira de valor econômico atual ou potencial. Plantas para o futuro, Região Sul. Brasília: MMA, 2011. p. 507511.

SOBRAL, M.; JARENKOW, J.A.; BRACK, P.; IRGANG, B.; LAROCCA, J.; RODRIGUES, R.S. Flora arbórea e arborescente do Rio Grande do Sul, Brasil. São Carlos: RiMa : Novo Ambiente, 2006. 350 p. 